-Note-

\title{
Nasal colonization and antibiotic resistance patterns of Staphylococcus species isolated from healthy horses in Tripoli, Libya
}

\author{
Aesha A. OTHMAN ${ }^{1}$, Murad A. HIBLU ${ }^{2}$, Mohamed Salah ABBASSI ${ }^{3}$, Yousef M. ABOUZEED ${ }^{1}$ \\ and Mohamed O. AHMED ${ }^{1 *}$ \\ ${ }^{1}$ Department of Microbiology and Parasitology, Faculty of Veterinary Medicine, University of Tripoli, P.O. Box \\ 13362, Libya \\ ${ }^{2}$ Department of Internal Medicine, Faculty of Veterinary Medicine, University of Tripoli, P.O. Box 13662, Libya \\ ${ }^{3}$ University of Tunis El Manar, Institute of Veterinary Research of Tunisia, Tunis 1006, Tunisia
}

The present study investigated the colonization rates and antimicrobial susceptibility of Staphylococcus species isolated from the nostrils of healthy horses. A nonselective laboratory approach was applied, followed by confirmation using a Phoenix automated microbiological system. Among the 92 horses included in the study, 48.9\% (45/92) carried Staphylococcus species of mostly the coagulase-negative staphylococci (CoNS) type yielding 70 Staphylococcus strains. Of these strains, 37.1\% (26/70; 24 CoNS and 2 coagulasepositive staphylococci; CoPS) were identified as methicillin-resistant staphylococci (MRS) expressing significant resistance to important antimicrobial classes represented mainly by subspecies of CoNS. This is the first study reporting a high prevalence of various Staphylococcus species, particularly strains of CoNS expressing multidrug resistance patterns of public health concern, colonizing healthy horses in Libya.

Key words: antimicrobial resistance, coagulase-negative staphylococci, healthy horse, nasal colonization, Libya

Methicillin-resistant staphylococci (MRS) of clinical and public health concern have been increasingly reported in horses [17]. They have been reported in the skin and nasal passages of horses infected with diverse staphylococci causing opportunistic and zoonotic infections, such as methicillin-resistant Staphylococcus aureus (MRSA) and methicillin-resistant coagulase-negative staphylococci (MRCoNS) [18, 19, 22]. These pathogens are widely reported to have variable geographic distributions worldwide in clinical and healthy horses [16].

The current study investigated the prevalence and antimicrobial susceptibility of Staphylococcus species isolated

Received: October 27, 2020

Accepted: April 9, 2021

*Corresponding author. e-mail:

a.mo@live.com; m.ahmed@uot.edu.ly

(C2021 Japanese Society of Equine Science

This is an open-access article distributed under the terms of the Creative Commons Attribution Non-Commercial No Derivatives (by-nc-nd) License. (CC-BY-NC-ND 4.0: https://creativecommons.org/licenses/ by-nc-nd/4.0/)

\author{
J. Equine Sci. \\ Vol. 32, No. 2 \\ pp. 61-65, 2021
}

from the nostrils of 92 healthy horses from four locations in Tripoli in January-February 2018. The inclusion criteria for the horses were no signs of any illnesses and no treatment with any medications, including antimicrobials, for at least three months prior to this study. The ages of the included horses ranged from 0.3 to 24 years (mean, 7.5 years), and the sex distribution was $77.2 \%(n=71)$ female and $22.8 \%$ $(n=21)$ male. The breeds of the horses included Thoroughbreds $(n=81,88.0 \%)$, English $(n=3,3.3 \%)$, Arabians $(n=1$, $1.1 \%)$, and half-breeds $(n=1,1.1 \%)$. The remaining $6(6.5 \%)$ horses were of unspecified breeds. The study was approved and registered by the Postgraduate Studies Department of the Ministry of Education, Libya (Reference number, 14144). The purpose of the study and benefits of participation were explained to all owners before the study, and informed consent was obtained.

A total of two nasal specimens were obtained from the nostrils of each horse using moist sterile cotton-tipped (in-house) swabs. Each swab was inserted approximately $10 \mathrm{~cm}$, pressed slightly against the mucosa, and then transferred to the laboratory and processed within $4 \mathrm{hr}$. 
Samples were streaked onto mannitol-salt agar and blood agar, respectively, and then incubated for $24-48 \mathrm{hr}$ at $35^{\circ} \mathrm{C}$. A typical colony was selected from each plate and further examined with a Gram stain and catalase test. Presumptive staphylococci isolates were further tested with a BD Phoenix automated identification and susceptibility testing system (PAMS, MSBD Biosciences, Sparks, MD, U.S.A.) for definite characterization at the genus and species levels and to determine the susceptibility against antimicrobial agents.

The antimicrobial susceptibility profiles of confirmed staphylococci and the decision of MRS were carryed out based on the interpretation of the Phoenix system according to the CLSI guidelines [10]. The Fisher's exact test was used to analyse data and compare the proportions of colonization rates of Staphylococcus species. $P$-values $\leq 0.05$ were considered statistically significant.

Staphylococcus species were recovered from $48.9 \%$ $(45 / 92)$ of the horses (mean age, 7 years; range, 0.4 to 23 years). The rate of colonization in male horses was $33.3 \%$ $(7 / 21)$, whereas it was $53.5 \%(38 / 71)$ in female horses $(P>0.05)$. In total, $27.2 \%(25 / 92)$ of the horses tested positive in both nostrils, whereas $21.7 \%$ (20/92) of the horses tested positive carrier in a single nostril. Among the total positive horses, 91.1\% (41/45) were colonized with a single type of staphylococci; $84.4 \%$ (38/45) of the horses were only colonized with CoNS, whereas $6.7 \%$ (3/45) of the horses were only colonized with CoPS. The remaining $8.9 \%(4 / 45)$ of the horses were colonized with different Staphylococcus species.

Furthermore, $46.7 \%(21 / 45)$ of the colonized horses carried two similar species of staphylococci (20 horses carried two different CoNS species, and one horse carried two different CoPS species), whereas 44.4\% (20/45) carried a single species of staphylococci only (18 horses with a CoNS species and 2 horses with a CoPS species; $P>0.05)$. The process yielded 70 Staphylococcus strains, of which $37.1 \%(26 / 70)$ expressed typical MRS phenotypes representing $21.7 \%$ (20/92) of the total horses; 18 of the 20 horses were CoNS carriers (8 carrying a single species; 10 carrying two species), and the other two $(n=2)$ comprised a CoPS carrier and a horse carrying a different species. The 70 Staphylococcus species were represented by 17 different species of staphylococci, including 15 species of CoNS ( $n=62)$ and two subspecies of CoPS ( $n=8$; Table 1). Furthermore, the $37.1 \%(26 / 70 ; 24$ CoNS and 2 CoPS) of the strains expressing MRS phenotypes were found to have similar antibiogram profiles (Table 2).

The present study revealed high colonization rate of staphylococci compared with regional data [12]; 27.2\% of the horses were colonized in both nostrils, and $21.7 \%$ of the horses were colonized in a single nostril, mostly by CoNS,
Table1. Proportion and features of isolated Staphylococcus species

\begin{tabular}{lcc}
\hline Staphylococcus spp. & No. of isolates & No. of MRS \\
\hline S. xylosus & 12 & 2 \\
S. sciuri & 8 & 2 \\
S. equorum & 8 & 2 \\
S. lentus & 5 & 5 \\
S. simulans & 5 & 0 \\
S. gallinarum & 5 & 0 \\
S. chromogenes & 4 & 4 \\
S. saprophyticus & 3 & 2 \\
S. felis & 2 & 2 \\
S. warneri & 2 & 0 \\
S. pasteuri & 2 & 2 \\
S. haemolyticus & 2 & 2 \\
S. schleiferi & 2 & 0 \\
S. carnosus & 1 & 1 \\
S. kloosii & 1 & 0 \\
\hline Total of CoNS & 62 & 24 \\
\hline S. aureus & 5 & 2 \\
S. intermedius & 3 & 0 \\
\hline Total of CoPS & 8 & 2
\end{tabular}

MRS, methicillin-resistant staphylococci; CoPS, coagulase-positive staphylococci; CoNS, coagulase-negative staphylococci.

which accounted for $84.4 \%$ of the horses testing positive. Strains of the $S$. sciuri group and S. xylosus are commensal bacteria of the skin and mucous membranes of different animal species, particularly horses, causing opportunistic infections in animals (e.g., mastitis or dermatitis) and zoonotic infections in humans in direct contact with them $[14,25]$. S. xylosus is frequently isolated from animal products (e.g., cheese, milk, and meat products) and further used in the development of flavour and food processing [11].

In Africa, reports of MRS and MRSA in equine populations are very rare, and the reported colonization rate in the current study is higher compared with that in a regional report [12]. In the current study, most of the horses colonized with MRS were colonized with the CoNS group, mainly represented by the $S$. sciuri group. Such finding has reportedly been linked to antibiotic selection pressure as well as a previous history of prolonged antibiotic treatments, hospitalization, and transportation stress [20-22].

Horses are frequently colonized with diverse CoNS strains found in healthy and clinical animals showing concerning multidrug resistance phenotypes with variable epidemiological distribution [1]. For instance, higher prevalences of CoNS and MRCoNS and no/low prevalence of MRSA have been reported in healthy horses in the Netherlands [7, 9]. In Africa, 6 to $68 \%$ of suspected human infections and $3 \%$ to $61.7 \%$ of suspected animal infections are reported to be caused by CoNS (e.g., S. epidermidis, S. haemolyticus, S. capitis, S. lugdunensis, and S. xylosus) 
Table 2. Antimicrobial susceptibility profiling of 26 methicillin-resistant staphylococci (MRS) strains

\begin{tabular}{|c|c|c|c|}
\hline Staphylococcus spp. & Resistant & Intermediate & Susceptible \\
\hline S. lentus (MLSB) & IPM, FOX, CTX, AMP, PenG, OXA, AMX & ERY, CLI & $\begin{array}{l}\text { GEN, DAP, STX, TEC, VAN, LZD, MUP, } \\
\text { NFZ, CIP, MXF, RIF, TET }\end{array}$ \\
\hline S. saprophyticus & $\begin{array}{l}\text { IPM, FOX, CTX, AMP, PenG, OXA, AMX, } \\
\text { FUS }\end{array}$ & $\mathrm{N}$ & $\begin{array}{l}\text { GEN, DAP, STX, TEC, VAN, LZD, MUP, } \\
\text { NFZ, CIP, MXF, RIF, TET, ERY, CLN }\end{array}$ \\
\hline S. saprophyticus & $\begin{array}{l}\text { IPM, FOX, CTX, AMP, PenG, OXA, AMX, } \\
\text { FUS }\end{array}$ & $\mathrm{N}$ & $\begin{array}{l}\text { GEN, DAP, STX, TEC, VAN, LZD, MUP, } \\
\text { NFZ, CIP, MXF, RIF, TET, ERY, CLN }\end{array}$ \\
\hline S. xylosus & IPM, FOX, CTX, AMP, PenG, OXA, AMX & $\mathrm{N}$ & $\begin{array}{l}\text { GEN, DAP, STX, TEC, VAN, LZD, MUP, } \\
\text { NFZ, CIP, MXF, RIF, TET, ERY, CLN }\end{array}$ \\
\hline S. chromogenes & IPM, FOX, CTX, AMP, PenG, OXA, AMX & $\mathrm{N}$ & $\begin{array}{l}\text { GEN, DAP, STX, TEC, VAN, LZD, MUP, } \\
\text { NFZ, CIP, MXF, RIF, TET, ERY, CLN }\end{array}$ \\
\hline S. lentus & IPM, FOX, CTX, AMP, PenG, OXA, AMX & $\mathrm{N}$ & $\begin{array}{l}\text { GEN, DAP, STX, TEC, VAN, LZD, MUP, } \\
\text { NFZ, CIP, MXF, RIF, TET, ERY, CLN }\end{array}$ \\
\hline S. chromogenes & IPM, FOX, CTX, AMP, PenG, OXA, AMX & $\mathrm{N}$ & $\begin{array}{l}\text { GEN, DAP, STX, TEC, VAN, LZD, MUP, } \\
\text { NFZ, CIP, MXF, RIF, TET, ERY, CLN }\end{array}$ \\
\hline S. chromogenes & IPM, FOX, CTX, AMP, PenG, OXA, AMX & $\mathrm{N}$ & $\begin{array}{l}\text { GEN, DAP, STX, TEC, VAN, LZD, MUP, } \\
\text { NFZ, CIP, MXF, RIF, TET, ERY, CLN }\end{array}$ \\
\hline S. pasteuri (MLSB) & $\begin{array}{l}\text { IPM, FOX, CTX, AMP, PenG, OXA, AMX, } \\
\text { CLI, ERY }\end{array}$ & $\mathrm{N}$ & $\begin{array}{l}\text { GEN, DAP, STX, TEC, VAN, LZD, MUP, } \\
\text { NFZ, CIP, MXF, RIF, TET }\end{array}$ \\
\hline S. lentus & IPM, FOX, CTX, AMP, PenG, OXA, AMX & $\mathrm{N}$ & $\begin{array}{l}\text { GEN, DAP, STX, TEC, VAN, LZD, MUP, } \\
\text { NFZ, CIP, MXF, RIF, TET, ERY, CLN }\end{array}$ \\
\hline S. lentus & IPM, FOX, CTX, AMP, PenG, OXA, AMX & $\mathrm{N}$ & $\begin{array}{l}\text { GEN, DAP, STX, TEC, VAN, LZD, MUP, } \\
\text { NFZ, CIP, MXF, RIF, TET, ERY, CLN }\end{array}$ \\
\hline S. schleiferi & IPM, FOX, CTX, AMP, PenG, OXA, AMX & $\mathrm{N}$ & $\begin{array}{l}\text { GEN, DAP, STX, TEC, VAN, LZD, MUP, } \\
\text { NFZ, CIP, MXF, RIF, TET, ERY, CLN }\end{array}$ \\
\hline S. equorum & IPM, FOX, CTX, AMP, PenG, OXA, AMX & $\mathrm{N}$ & $\begin{array}{l}\text { GEN, DAP, STX, TEC, VAN, LZD, MUP, } \\
\text { NFZ, CIP, MXF, RIF, TET, ERY, CLN }\end{array}$ \\
\hline S. carnosus & IPM, FOX, CTX, AMP, PenG, OXA, AMX & $\mathrm{N}$ & $\begin{array}{l}\text { GEN, DAP, STX, TEC, VAN, LZD, MUP, } \\
\text { NFZ, CIP, MXF, RIF, TET, ERY, CLN }\end{array}$ \\
\hline S. pasteuri & IPM, FOX, CTX, AMP, PenG, OXA, AMX & ERY & $\begin{array}{l}\text { GEN, DAP, STX, TEC, VAN, LZD, MUP, } \\
\text { NFZ, CIP, MXF, RIF, TET, CLIN }\end{array}$ \\
\hline S. sciuri & IPM, FOX, CTX, AMP, PenG, OXA, AMX & $\mathrm{N}$ & $\begin{array}{l}\text { GEN, DAP, STX, TEC, VAN, LZD, MUP, } \\
\text { NFZ, CIP, MXF, RIF, TET, ERY, CLN }\end{array}$ \\
\hline S. lentus & IPM, FOX, CTX, AMP, PenG, OXA, AMX & $\mathrm{N}$ & $\begin{array}{l}\text { GEN, DAP, STX, TEC, VAN, LZD, MUP, } \\
\text { NFZ, CIP, MXF, RIF, TET, ERY, CLN }\end{array}$ \\
\hline S. xylosus & IPM, FOX, CTX, AMP, PenG, OXA, AMX & $\mathrm{N}$ & $\begin{array}{l}\text { GEN, DAP, STX, TEC, VAN, LZD, MUP, } \\
\text { NFZ, CIP, MXF, RIF, TET, ERY, CLN }\end{array}$ \\
\hline S. aureus & IPM, FOX, CTX, AMP, PenG, OXA, AMX & $\mathrm{N}$ & $\begin{array}{l}\text { GEN, DAP, STX, TEC, VAN, LZD, MUP, } \\
\text { NFZ, CIP, MXF, RIF, TET, ERY, CLN }\end{array}$ \\
\hline S. schleiferi & IPM, FOX, CTX, AMP, PenG, OXA, AMX & $\mathrm{N}$ & $\begin{array}{l}\text { GEN, DAP, STX, TEC, VAN, LZD, MUP, } \\
\text { NFZ, CIP, MXF, RIF, TET, ERY, CLN }\end{array}$ \\
\hline S. aureus & IPM, FOX, CTX, AMP, PenG, OXA, AMX & CLI & $\begin{array}{l}\text { GEN, DAP, STX, TEC, VAN, LZD, MUP, } \\
\text { NFZ, CIP, MXF, RIF, TET, ERY }\end{array}$ \\
\hline S. equorum & IPM, FOX, CTX, AMP, PenG, OXA, AMX & CLI & $\begin{array}{l}\text { GEN, DAP, STX, TEC, VAN, LZD, MUP, } \\
\text { NFZ, CIP, MXF, RIF, TET, ERY }\end{array}$ \\
\hline S. felis & IPM, FOX, CTX, AMP, PenG, OXA, AMX & $\mathrm{N}$ & $\begin{array}{l}\text { GEN, DAP, STX, TEC, VAN, LZD, MUP, } \\
\text { NFZ, CIP, MXF, RIF, TET, ERY, CLN }\end{array}$ \\
\hline S. sciuri & IPM, FOX, CTX, AMP, PenG, OXA, AMX & $\mathrm{N}$ & $\begin{array}{l}\text { GEN, DAP, STX, TEC, VAN, LZD, MUP, } \\
\text { NFZ, CIP, MXF, RIF, TET, ERY, CLN }\end{array}$ \\
\hline S. felis & IPM, FOX, CTX, AMP, PenG & $\mathrm{N}$ & $\begin{array}{l}\text { GEN, DAP, STX, TEC, VAN, LZD, MUP, } \\
\text { NFZ, CIP, MXF, RIF, TET, ERY, CLN }\end{array}$ \\
\hline S. chromogenes & IPM, FOX, CTX, AMP, PenG, OXA, AMX & $\mathrm{N}$ & $\begin{array}{l}\text { GEN, DAP, STX, TEC, VAN, LZD, MUP, } \\
\text { NFZ, CIP, MXF, RIF, TET, ERY, CLN }\end{array}$ \\
\hline
\end{tabular}

The 26 typical MRS isolates originated from 20 horses; 18 were CoNS carriers, and two were carriers of CoPS and a different species, respectively. N, not available; IPM, Imipenem; FOX, cefoxitin; CTX, cefotaxime; AMP, ampicillin; PenG, penicillin G; AMX, amoxicillin and clavulanic acid; OXA, oxacillin; ERY, erythromycin; CLI, clindamycin; TET, tetracycline; STX, trimethoprim-sulfamethoxazole; GEN, gentamicin; CIP, ciprofloxacin; NFZ, nitrofurazone; MUP, mupirocin; FUS, fusidic acid; LZD, linezolid; RIF, rifampin; DAP, daptomycin; VAN, vancomycin; TEC, teicoplanin; MXF, moxifloxacin. 
mainly from food-producing animals, with limited available information on companion and pet animals [5]. In Libya, MRSA is the most reported nosocomial pathogen exclusively isolated from human healthcare settings; however, critical multidrug-resistant Gram-negative rods and vancomycin-resistant enterococci (VRE) have recently emerged [2-4]. A novel recent study from Libya involving healthy and clinical cats and dogs revealed high colonization rates of various Staphylococcus species showing high multidrug (i.e., methicillin) resistance patterns and belong mainly to CoNS species (MRCoNS) [13].

CoNS are recognized as a reservoir of virulent and antibiotic resistance genes that can be acquired by other staphylococci mainly through the transconjugant transfer of the staphylococcal cassette chromosome mec(SCCmec) transposon containing the mecA gene, as in the case of transfer between $S$. aureus and S. epidermidis [24]. Another $m e c$ gene homolog, which is currently designated as mec $\mathrm{C}$ and has about $70 \%$ comparability with the mecA gene, was identified in 2011, and it carried by SCCmec elements isolated from animals, human clinical specimens, and the environment [8]. Unfortunately, due to the limitations of the current study, these important and widely reported genes were not investigated within the studied collection.

Antimicrobial susceptibility testing of Staphylococcus species could provide empirical data to guide therapy and overcome recurrent infections; however, other factors should be taken into consideration, such as the infection site, infection type, age, and health status [1]. For instance, the response to fluoroquinolone therapy for MRS is unpredictable despite in vitro susceptibility, and resistance may develop during antibiotic therapy [23]. Although suitable antimicrobials, such as chloramphenicol and trimethoprimsulfonamide can be used, the use of other critically important drugs, such vancomycin, linezolid, mupirocin, rifampin, and fusidic acid, should be limited due to the controversial nature of their use in horses and importance to human medicine. In addition, controlling the colonization of MRS in horses is problematic because transient colonization can be normal in horses, and thus decolonization with an antimicrobial therapy is not recommended [23].

Staphylococcus species of veterinary origin are difficult to characterize due to the lack of developed diagnostic protocols [15]. The automated Phoenix system has been widely used as an effective tool to identify species of staphylococci and determine antimicrobial susceptibility; however, a few species are not easy to identify [6]. For instance, $S$. pseudintermedius is frequently misdiagnosed as $S$. aureus due to their close phenotypic characteristics, which require advanced molecular protocols for a definite identification, such as PCR and matrix assisted laser desorption ionization-time of flight mass spectrometry (MALDI-
TOF MS) technology [15]. Furthermore, the current findings reveal the need to follow therapeutic guidelines and control and prevention measures to minimize the spread of Staphylococcus species with antimicrobial resistance. Further analyses of MRS colonization and transmission and the associated risk factors are required in equine medicine adopting the One Health concept.

\section{References}

1. Adams, R., Smith, J., Locke, S., Phillips, E., Erol, E., Carter, C., and Odoi, A. 2018. An epidemiologic study of antimicrobial resistance of Staphylococcus species isolated from equine samples submitted to a diagnostic laboratory. BMC Vet. Res. 14: 42. [Medline] [CrossRef]

2. Ahmed, M.O., and Baptiste, K.E. 2018. Vancomycinresistant enterococci: a review of antimicrobial resistance mechanisms and perspectives of human and animal health. Microb. Drug Resist. 24: 590-606. [Medline] [CrossRef]

3. Ahmed, M.O., Baptiste, K.E., Daw, M.A., Elramalli, A.K., Abouzeed, Y.M., and Petersen, A. 2017. Spa typing and identification of pvl genes of meticillin-resistant Staphylococcus aureus isolated from a Libyan hospital in Tripoli. $J$. Glob. Antimicrob. Resist. 10: 179-181. [Medline] [CrossRef]

4. Ahmed, M.O., Elramalli, A.K., Baptiste, K.E., Daw, M.A., Zorgani, A., Brouwer, E., Willems, R.J.L., and Top, J. 2020. Whole genome sequence analysis of the first vancomycin-resistant Enterococcus faecium isolates from a Libyan Hospital in Tripoli. Microb. Drug Resist. 26: 1390-1398. [Medline] [CrossRef]

5. Asante, J., Amoako, D.G., Abia, A.L.K., Somboro, A.M., Govinden, U., Bester, L.A., and Essack, S.Y. 2020. review of clinically and epidemiologically relevant coagulasenegative staphylococci in Africa. Microb. Drug Resist. 26: 951-970. [Medline] [CrossRef]

6. Bannoehr, J., Ben Zakour, N.L., Waller, A.S., Guardabassi, L., Thoday, K.L., van den Broek, A.H., and Fitzgerald, J.R. 2007. Population genetic structure of the Staphylococcus intermedius group: insights into agr diversification and the emergence of methicillin-resistant strains. J. Bacteriol. 189: 8685-8692. [Medline] [CrossRef]

7. Baptiste, K.E., Williams, K., Willams, N.J., Wattret, A., Clegg, P.D., Dawson, S., Corkill, J.E., O’Neill, T., and Hart, C.A. 2005. Methicillin-resistant staphylococci in companion animals. Emerg. Infect. Dis. 11: 1942-1944. [Medline] [CrossRef]

8. Bietrix, J., Kolenda, C., Sapin, A., Haenni, M., Madec, J.Y., Bes, M., Dupieux, C., Tasse, J., and Laurent, F. 2019. Persistence and Diffusion of mecC-Positive CC130 MRSA Isolates in Dairy Farms in Meurthe-et-Moselle County (France). Front. Microbiol. 10: 47. [Medline] [CrossRef]

9. Busscher, J.F., van Duijkeren, E., and Sloet van Oldruitenborgh-Oosterbaan, M.M. 2006. The prevalence of 
methicillin-resistant staphylococci in healthy horses in the Netherlands. Vet. Microbiol. 113: 131-136. [Medline] [CrossRef]

10. CLSI 2017. Clinical and Laboratory Standards Institute (CLSI); Performance Standards for Antimicrobial Susceptibility Testing, 27th ed., CLSI supplement M100.

11. Coton, E., Desmonts, M.H., Leroy, S., Coton, M., Jamet, E., Christieans, S., Donnio, P.Y., Lebert, I., and Talon, R. 2010. Biodiversity of coagulase-negative Staphylococci in French cheeses, dry fermented sausages, processing environments and clinical samples. Int. J. Food Microbiol. 137: 221-229. [Medline] [CrossRef]

12. De Martino, L., Lucido, M., Mallardo, K., Facello, B., Mallardo, M., Iovane, G., Pagnini, U., Tufano, M.A., and Catalanotti, P. 2010. Methicillin-resistant staphylococci isolated from healthy horses and horse personnel in Italy. J. Vet. Diagn. Invest. 22: 77-82. [Medline] [CrossRef]

13. Elnageh, H.R., Hiblu, M.A., Abbassi, M.S., Abouzeed, Y.M., and Ahmed, M.O. 2021. Prevalence and antimicrobial resistance of Staphylococcus species isolated from cats and dogs. Open Vet. J. 10: 452-456. [Medline] [CrossRef]

14. Giordano, N., Corallo, C., Miracco, C., Papakostas, P., Montella, A., Figura, N., and Nuti, R. 2016. Erythema nodosum associated with Staphylococcus xylosus septicemia. J. Microbiol. Immunol. Infect. 49: 134-137. [Medline] [CrossRef]

15. Guardabassi, L., Damborg, P., Stamm, I., Kopp, P.A., Broens, E.M., Toutain, P.L., ESCMID Study Group for Veterinary Microbiology 2017. Diagnostic microbiology in veterinary dermatology: present and future. Vet. Dermatol. 28: 146-e30. [Medline] [CrossRef]

16. Karakulska, J., Fijałkowski, K., Nawrotek, P., Pobucewicz, A., Poszumski, F., and Czernomysy-Furowicz, D. 2012. Identification and methicillin resistance of coagulase-negative staphylococci isolated from nasal cavity of healthy horses. J. Microbiol. 50: 444-451. [Medline] [CrossRef]

17. Maddox, T.W., Clegg, P.D., Williams, N.J., and Pinchbeck, G.L. 2015. Antimicrobial resistance in bacteria from horses: epidemiology of antimicrobial resistance. Equine Vet. J. 47: 756-765. [Medline] [CrossRef]

18. Mama, O.M., Gómez, P., Ruiz-Ripa, L., Gómez-Sanz,
E., Zarazaga, M., and Torres, C. 2019. Antimicrobial resistance, virulence, and genetic lineages of staphylococci from horses destined for human consumption: high detection of $S$. aureus isolates of lineage ST1640 and those carrying the lukPQ gene. Animals (Basel) 9: 900. [Medline] [CrossRef]

19. Oguttu, J.W., Qekwana, D.N., and Odoi, A. 2017. An exploratory descriptive study of antimicrobial resistance patterns of staphylococcus spp. isolated from horses presented at a veterinary teaching hospital. BMC Vet. Res. 13: 269. [Medline] [CrossRef]

20. Schnellmann, C., Gerber, V., Rossano, A., Jaquier, V., Panchaud, Y., Doherr, M.G., Thomann, A., Straub, R., and Perreten, V. 2006. Presence of new mecA and $\mathrm{mph}(\mathrm{C})$ variants conferring antibiotic resistance in Staphylococcus spp. isolated from the skin of horses before and after clinic admission. J. Clin. Microbiol. 44: 4444-4454. [Medline] [CrossRef]

21. Van den Eede, A., Martens, A., Floré, K., Denis, O., Gasthuys, F., Haesebrouck, F., Van den Abeele, A., and Hermans, K. 2013. MRSA carriage in the equine community: an investigation of horse-caretaker couples. Vet. Microbiol. 163: 313-318. [Medline] [CrossRef]

22. van Duijkeren, E., Ten Horn, L., Wagenaar, J.A., de Bruijn, M., Laarhoven, L., Verstappen, K., de Weerd, W., Meessen, N., and Duim, B. 2011. Suspected horse-to-human transmission of MRSA ST398. Emerg. Infect. Dis. 17: 1137-1139. [Medline] [CrossRef]

23. Weese, S. 2009. Therapeutics in practice-treating methicillin-resistant Staphylococcus aureus. Infection 4: 6.

24. Xu, Z., Shah, H.N., Misra, R., Chen, J., Zhang, W., Liu, Y., Cutler, R.R., and Mkrtchyan, H.V. 2018. The prevalence, antibiotic resistance and $m e c A$ characterization of coagulase negative staphylococci recovered from non-healthcare settings in London, UK. Antimicrob. Resist. Infect. Control 7: 73. [Medline] [CrossRef]

25. Yasuda, R., Kawano, J., Matsuo, E., Masuda, T., Shimizu, A., Anzai, T., and Hashikura, S. 2002. Distribution of mecA-harboring staphylococci in healthy mares. J. Vet. Med. Sci. 64: 821-827. [Medline] [CrossRef] 